\title{
Assessing the potential for pyrocumulonimbus occurrence using simple fire weather indices
}

\author{
$\underline{\text { Jason J. Sharples }}^{\text {a,b }}$ (D) and Richard H.D. McRae ${ }^{a}$ \\ ${ }^{a}$ School of Science, University of New South Wales, Canberra, Australia \\ ${ }^{b}$ ARC Centre of Excellence for Climate Extremes, UNSW Canberra, ACT, Australia \\ Email:j.sharples@adfa.edu.au
}

\begin{abstract}
Pyrocumulonimbus (pyroCb) events occur when a thunderstorm forms within the plume of an active wildfire. These events have received considerable research interest over the last decade, mainly due to an apparent increase in their occurrence and for the fact that they constitute a significant and dangerous escalation in the state of a wildfire. PyroCbs form a subset of the class of extreme wildfires, which are defined by their intense and expansive flaming and the fact that they interact significantly with the surrounding atmosphere, resulting in the development of violent pyroconvection. Extreme wildfires consistently result in the most devastating socioeconomic and environmental impacts.
\end{abstract}

Researchers have developed several different tools for anticipating elements of pyroCb development, including FireCAPE and the pyroCb firepower threshold. These concepts have proven useful but require data and specialist technical capabilities than may not be readily available to operational personnel; for example, ground crews in Australia typically only have access to forecast surface conditions such as temperature, relative humidity and wind speed, and lower atmospheric conditions such as described by the continuous Haines index, communicated through hourly fire weather updates. Even well-resourced incident management teams may be challenged by the technical demands of implementing such measures.

In this paper we examine the potential of some simple fire weather indices to identify conditions conducive to pyroCb development. We consider the fuel moisture index $(F M I)$, the spread index $(S(\mu))$, the hot-dry-windy index $(H D W)$, and the con tinuous Haines ind ex (cHaines) and ass ess the ir abi lity to dis cern ins tances of pyroCb that occurred during the 2019/20 Australian 'Black Summer'. Specifically, we focus on pyroCbs that occurred in NSW over the three-month period of 1November 2019 - 31 January 2020.

The fuel moisture index and continuous Haines index performed the best at discriminating conditions conducive to pyroCb development: pyroCbs occurred only on days with $F M I<6$ and cHaines $\geq 8$. The spread index and HDW performed less well, most likely because of their incorporation of wind speed, which can actually work against pyroCb development. These results need to be investigated further, because in this initial analysis $H D W$ was only calculated using surface conditions rather than the maximal conditions within a 500-metre layer of the atmosphere, as required by its strict definition. Interestingly, it was also found that, to a very good approximation, $H D W$ is a special case of the spread index; in fact:

$$
H D W \approx \frac{32 \max (1, U)}{F M I+17}=32 S(17) \text {. }
$$

Based on the performance of the simple indices, a novel index, $\mathcal{P}$, was defined as the quotient of the continuous Haines index and the fuel moisture index:

$$
\mathcal{P}=\frac{\text { cHaines }}{F M I}
$$

It was found that pyroCb occurrence was strongly associated with days for which $\mathcal{P} \geq 2$; that is, when the continuous Haines index was twice the fuel moisture index, or more.

The results presented here provide a parsimonious way for operational personnel to gauge the likelihood of pyroCb occurrence based on readily available daily forecast fire weather information. It is likely that these concepts can also be applied at finer temporal scales. Fire weather variables such as temperature and relative humidity (which can be easily combined to give $F M I$ ) and cHaines are routinely available in operational fire weather reports, and so "cHaines $\geq 2 \times F M I$ " provides a useful rule of thumb for assessing the likelihood of dangerous escalations in wildfire activity.

Keywords: Simple indices, fire weather, pyrocumulonimbus, model parsimony 


\section{INTRODUCTION}

Extreme wildfires are a worsening problem in many fire-prone parts of the globe. These fires consistently present the most significant threat to communities and result in the most devastating socioeconomic and environmental impacts (Sharples et al. 2016). Recently, there have been significant efforts dedicated to prediction of pyrocumulonimbus events (e.g., Tory and Kepert, 2021), which form a subset of the broader class of extreme wildfires. Pyrocumulonimbus (pyroCb) events are characterised by highly unpredictable fire behaviour and propagation, often associated with mass ember transport, and so there is interest in understanding when fires transition to pyroCb events, so that incident management plans can be appropriately revised in a proactive rather than reactive manner.

Existing approaches to diagnosing conditions that contribute to pyroCb formation, such as FireCAPE (Potter, 2005 ) and the pyroCb firepower threshold (Tory and Kepert, 2021) require access to data and further specialist input that may not be readily available, even to well-resourced incident management teams. In this paper, we examine a more parsimonious approach to assessing pyroCb potential using simple fire weather indices, which have been employed in other fire management contexts. In particular, we consider several pyroCbs that occurred over southeastern NSW during the 2019/20 'Black Summer' fire season and assess the ability of the simple indices to provide insights into the conditions necessary for pyroCb formation.

\section{THE BLACK SUMMER: FIRE WEATHER AND PYROCUMULONIMBUS DATA}

The 2019/20 fire season in southeastern Australia, known as the 'Black Summer', was unprecedented on a number of levels: the extensive area of forest burnt, the radiative power of the fires, and the extraordinary number of fires that developed into violent pyroconvective events were all unmatched in the historical record (Abram et al. 2021). Antecedent conditions were exceptionally dry - a combination of fire-promoting phases of climate variability and longer-term climate trends meant that 2019 was Australia's hottest and driest year on record. Even before the Black Summer, forested regions in Victoria had experienced an unseasonal spate of extreme wildfires in March 2019, including several instances of pyrocumulonimbus (pyroCb).

The most devastating instances of fire behaviour experienced during the Black Summer occurred on an episodic basis mainly over southeastern NSW and eastern Victoria. The antecedent drought had resulted in maximal fuel availability across the landscape, which when combined with critical fire weather produced catastrophic fire danger conditions. The critical fire weather was mostly associated with complex trough systems (regions of relatively lower pressure) ahead of synoptic cold fronts, which affected the region in recurrent episodes of heatwave conditions with strong north-westerly winds ahead of trough/frontal systems. Figure 1 shows a satellite picture of multiple large wildfires, including a pyroCb, burning across NSW and Victoria on 31 December 2019.

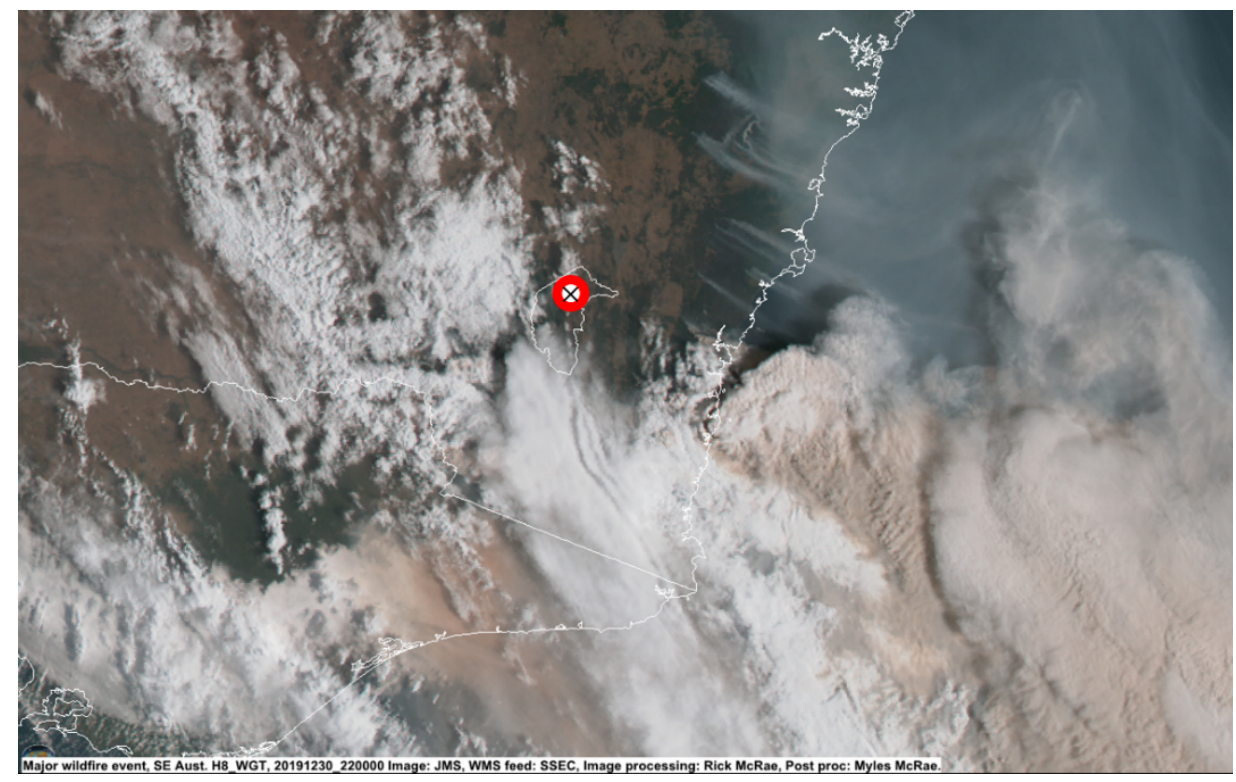

Figure 1. Large wildfire outbreak over NSW and Victoria, including a pyroCb, 31 December 2019. The marker indicates the location of Canberra, ACT. The image also shows a synoptic trough/front system (visible as the NW-SE oriented cloud band) moving over southeastern NSW. 
To examine the association of fire weather conditions with pyroCb occurrence we draw upon several data sources. In this initial analysis, we concentrate on surface fire weather conditions at Canberra (see Fig. 1) and take them to be broadly representative of the prevailing synoptic-scale conditions driving fire behaviour across southeast NSW. Specifically, we use daily observations of maximum temperature, 9am and 3pm relative humidity and maximum wind speed recorded at Canberra Airport. To assess the influence of mid-tropospheric conditions we also use sounding data recorded at Wagga Wagga, which is the nearest location to Canberra that such data are available (Wagga Wagga is about $160 \mathrm{~km}$ west of Canberra). We focus on the three-month (92 day) period: 1 November 2019 - 31 January 2020, during which all the pyroCb activity occurred over NSW. Unfortunately, the sounding data was only available for 69 out of the 92 days considered.

Pyrocumulonimbus occurrence was ascertained using the Australian PyroCb Register (McRae et al., 2015). This on-going register relies on expert analysis of information from a wide range of direct and remote observations to form a coherent picture of events, which are assessed against threshold criteria for pyroCb (Fromm et al., 2010). A total of 29 pyroCbs were identified over southeastern NSW during the period of interest. These occurred on 11 days out of the 92-day period, with some days recording multiple pyroCb events and pulses; for example, seven pyroCbs were identified on 30 December 2019, as part of the Black Summer pyroCb super outbreak (Peterson et al. 2021).

\section{SIMPLE FIRE WEATHER INDICES}

We examine the ability of several simple indices to identify instances of pyroCb occurrence over southeastern NSW during the Black Summer. The indices considered have been used to describe various aspects of fire weather and the fire environment, including fuel moisture content, rate of spread and the potential for especially dangerous fire behaviour and/or violent pyroconvective development.

\subsection{Fuel moisture index}

The fuel moisture index $(F M I)$ is a dimensionless index defined as a simple affine transformation of the difference between air temperature $T\left({ }^{\circ} \mathrm{C}\right)$ and relative humidity $H$ (\%) (Sharples et al. 2009):

$$
F M I=10-0.25(T-H) .
$$

While the FMI does not directly produce fuel moisture content values, it has been shown to provide an equivalent scale, or measure, for fine dead fuel moisture content (Sharples and McRae, 2011).

\subsection{Spread index}

The spread index $(S)$ is defined here as a one-parameter family of functions of wind speed $U\left(\mathrm{~km} \mathrm{~h}^{-1}\right)$ and the FMI (Sharples and McRae, 2013):

$$
S(\mu)=\frac{\max (1, U)}{F M I+\mu} .
$$

Note that the spread index has also been implemented as a two-parameter family of functions, e.g., Sharples (2019), but in the present work one parameter was found to be adequate. The spread index has been shown to be an accurate descriptor for rate of fire spread in a variety of different fuel types (Sharples and McRae, 2013; Sharples, 2019). For example, Sharples and McRae (2013) showed that $\mu=5$ produced an index that (modulo a curing-dependent scaling factor) accurately replicated predictions of more complex operational models for grassland rate of spread.

\subsection{Hot-dry-windy index}

The hot-dry-windy index (HDW) was introduced by Srock et al. (2018) who demonstrated its enhanced ability to distinguish days on which synoptic-and meso-scale weather processes can contribute to dangerous fire behaviour, compared to other indices that are commonly considered. $H D W$ is defined as the product of wind speed $U\left(\mathrm{~m} \mathrm{~s}^{-1}\right)$ and vapour pressure deficit $V P D(\mathrm{hPa})$ :

$$
H D W=V P D \times U .
$$

In the absence of direct measurements of the vapour pressure deficit, we calculate $V P D$ from air temperature $T$ and relative humidity $H$ using Tetens' formula for the saturation vapour pressure (Montieth and Unsworth, 2013): 


$$
V P D=6.1078 \exp \left(\frac{T}{17.27(T+237.3)}\right)\left(1-\frac{H}{100}\right) .
$$

To account for the potential for deeper layers of the atmosphere to affect a fire, Srock et al. (2018) defined $H D W$ over a 500-metre layer just above the surface, so that the values for $U$ and VPD used in the calculation of $H D W$ are the maximum values found within the 500-metre layer. However, due to the absence of observations of the atmospheric profile at Canberra, the present analysis only uses surface conditions to calculate $H D W$. The implications of this will be discussed in more detail in a later section.

\subsection{Continuous Haines index}

The continuous Haines (cHaines) index was calculated according to Mills and McCaw (2010) by adding the two terms $C A$ and $C B: C A$ is a stability term representing the difference between temperatures at $850 \mathrm{hPa}$ and $700 \mathrm{hPa}$; $C B$ is a dryness term representing the dewpoint depression at $850 \mathrm{hPa}$. The stability component is given by:

$$
C A=0.5\left(T_{850}-T_{700}\right)-2,
$$

where $T_{850}$ and $T_{700}$ denote air temperature at the $850 \mathrm{hPa}$ and $700 \mathrm{~h} \mathrm{~Pa}$ levels of the atmosphere, respectively. The dryness component is given by:

$$
C B= \begin{cases}C B^{*}, & \text { if } C B^{*} \leq 5 \\ 0.5\left(C B^{*}-5\right)+5, & \text { if } 5<C B^{*} \leq 9, \\ 9, & \text { if } C B^{*}>9\end{cases}
$$

where $C B^{*}$ is defined in terms of the temperature, $T_{850}$, and dewpoint temperature, $D_{850}$, at the $850 \mathrm{hPa}$ level, as:

$$
C B^{*}=0.33\left(T_{850}-D_{850}\right)-1 .
$$

\section{RESULTS AND DISCUSSION}

Figure 2 shows how the minimum daily FMI varied over the period 15 November 2019 - 10 January 2020. Note that the minimum FMI was calculated using the maximum daily temperature and the minimum of the $9 \mathrm{am}$ and $3 \mathrm{pm}$ relative humidity, and so is a conservative estimate of the daily minimum. The figure indicates that pyroCb occurrence was uniquely associated with days when the minimum $F M I<6$. According to Sharples et al. (2009), this corresponds to an exceptionally low dead fuel moisture content of less than around 4-5\%. Dead fuel moisture levels below 5\% have historically been associated with wildfires in southeast Australia that exhibit explosive fire growth with mass generation of embers and mass spotting, which can result in deep flaming and an increased likelihood of violent pyroconvection (Badlan et al. 2021).

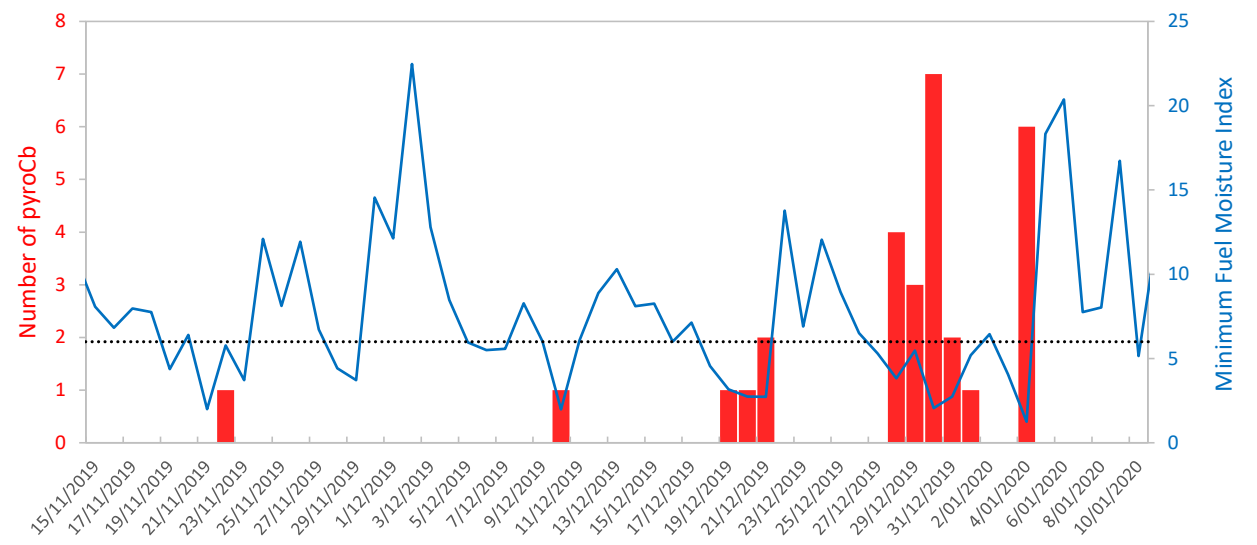

Figure 2. Time series of minimum FMI (blue) plotted against pyroCb occurrence data (red) for the period 15 November $2019-10$ January 2020. The black dotted line indicates a threshold of $F M I=6$.

Figure 3 shows the same information as Fig. 2 but for the maximum daily value of the spread index (calculated with $\mu=5$ ). Again, the maximum spread index values reported are conservative estimates - it is possible that the spread index may have attained larger daily values than those presented. The figure indicates that pyroCbs occurred on days when $S(5)$ was as low as 3 . However, $S(5) \geq 3$ for $79 \%$ days in the 92 -day period of interest, 
and so the spread index does not discriminate conditions necessary for pyroCb occurrence as well as the $F M I$, for which only $34 \%$ of days satisfied $F M I<6$.

Figure 4 shows how the maximum daily values of the $H D W$ index varied over 15 November 2019 - 10 January 2020 and indicates that pyroCbs occurred on days with values as low as $H D W \approx 45$. Again, this is not particularly useful for discriminating conditions necessary for pyroCb occurrence as $86 \%$ of days in the 92 day period satisfied $H D W>45$. We note that this result must be considered as preliminary, as $H D W$ was calculated using near-surface values of wind speed and vapour pressure deficit, rather than the maximum values within a 500-metre layer of the atmosphere. Examination of the Wagga Wagga profile data indicated that the maximum value of the wind speed within the 500-metre layer was equal to the surface wind speed on $63 \%$ of the days where data was available, hence further work is required to see whether more careful consideration of wind speed and VPD within the lowest 500 metres of the atmosphere would significantly alter the results presented here.

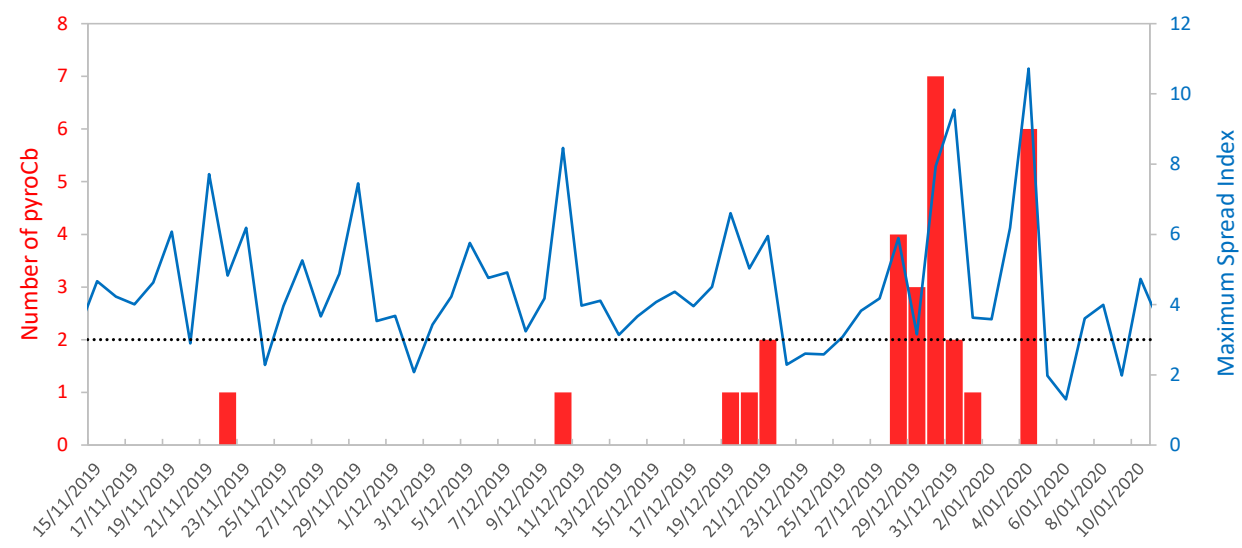

Figure 3. Time series of maximum spread index $S(5)$ (blue) plotted against pyroCb occurrence data (red) for the period 15 November 2019 - 10 January 2020. The black dotted line indicates a threshold of $S(5)=3$.

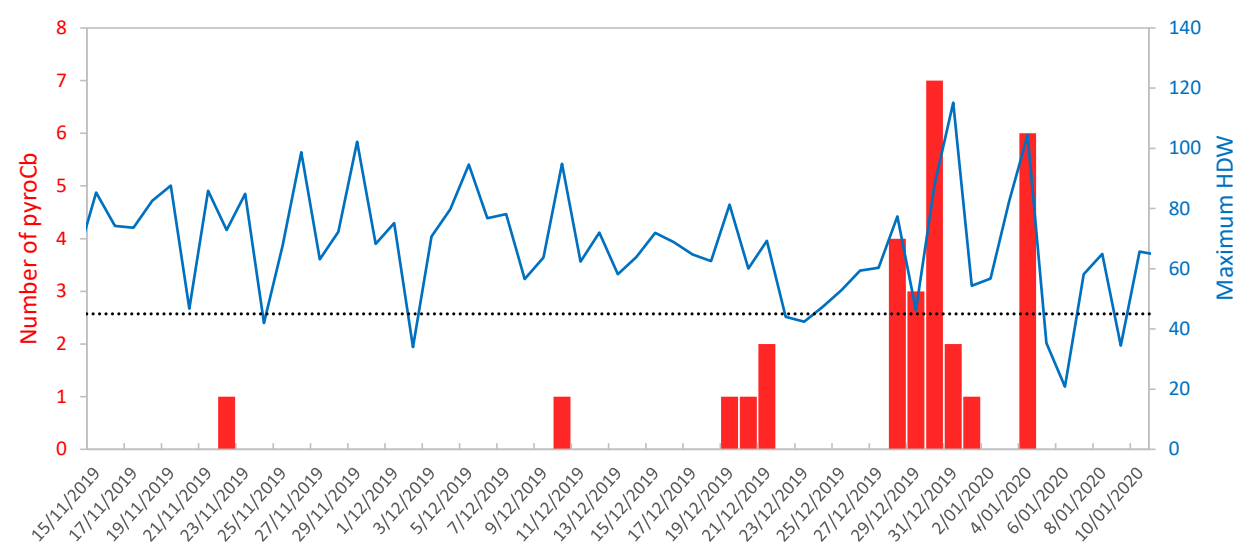

Figure 4. Time series of maximum $H D W$ (blue) plotted against pyroCb occurrence data (red) for the period 15 November 2019 - 10 January 2020. The black dotted line indicates a threshold of $H D W=45$.

It is of interest to point out the similarity between the spread index and $H D W$. Indeed, as indicated by Figure 5 , the $H D W$ index is well-estimated by a particular member of the one-parameter family of functions, namely the one corresponding to $\mu=17$. The figure shows values of the spread index (multiplied by 32) plotted against corresponding values of $H D W$. The correlation between the two sets of variables is $\rho=0.96$. Hence the spread index and $H D W$ essentially combine fire weather information in a similar way, and so provide similar guidance. Their poorer ability to discriminate conditions conducive to pyroCb is likely due to the incorporation of wind speed. As noted by other authors (e.g., Tory and Kepert 2021), strong winds can cause a wildfire's plume to lean over, making it less likely to reach levels of the atmosphere where secondary processes such as pyroCb take place. 


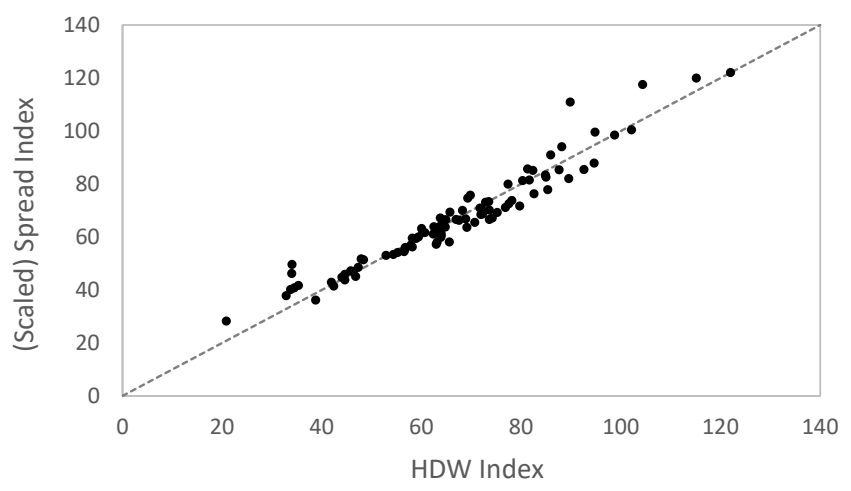

Figure 5. Scaled spread index values, $32 \times S(17)$, plotted against corresponding values of the hot-dry-windy index for each of the days in the period 1 November 2019 - 31 January 2020.

Figure 6 confirms that pyroCb development is associated with high cHaines values of about 8 or more, as has been reported by other authors (e.g., Di Virgilio et al., 2019). Moreover, cHaines $\geq 8$ occurred on only 32\% of the days considered, which means that it has similar discriminatory power to $F M I$. This observation suggests that a combination of cHaines and FMI might provide even better discrimination of conditions conducive to pyro $\mathrm{Cb}$ development, hence Figure 7 shows time series of cHaines divided by FMI. In this case, pyroCb days are well-identified by conditions corresponding to cHaines $\geq 2 \times F M I$. Note that this condition was satisfied on only $16 \%$ of the days considered and results in fewer 'false positives' than the condition cHaines $\geq 8$ alone. It should be noted, however, that the cHaines values used in this study are daily values calculated at Wagga Wagga, which do not necessarily reflect the potential spatial and temporal variability of cHaines values when and where pyroCbs occurred. This issue will be considered more deeply in further work.

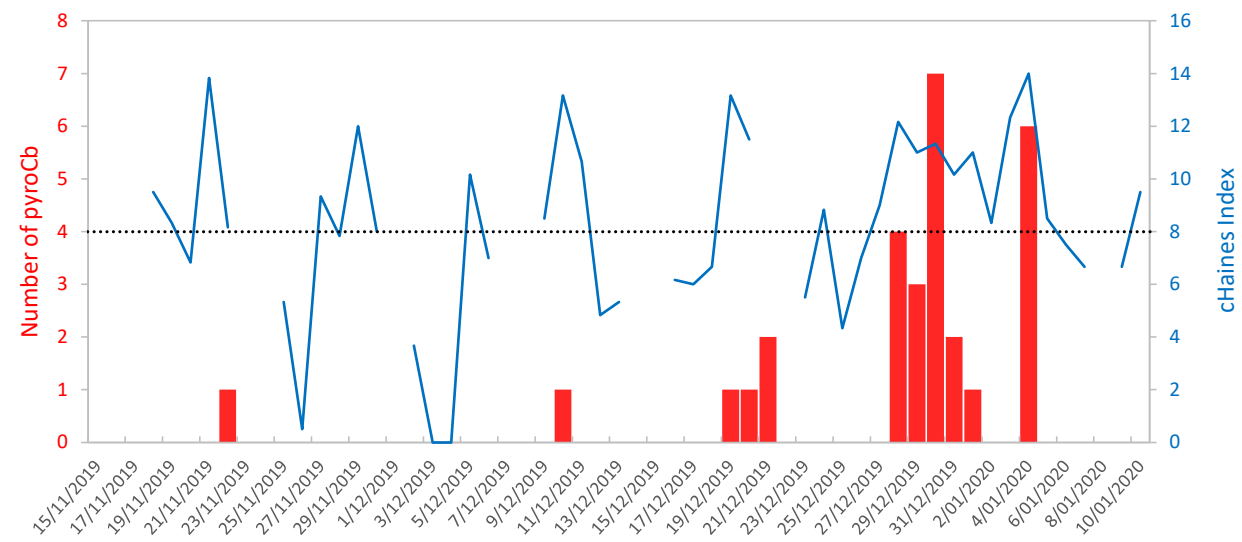

Figure 6. Time series of cHaines (blue) plotted against pyroCb occurrence data (red) for the period 15 November 2019 - 10 January 2020. The black dotted line indicates a threshold of cHaines $=8$.

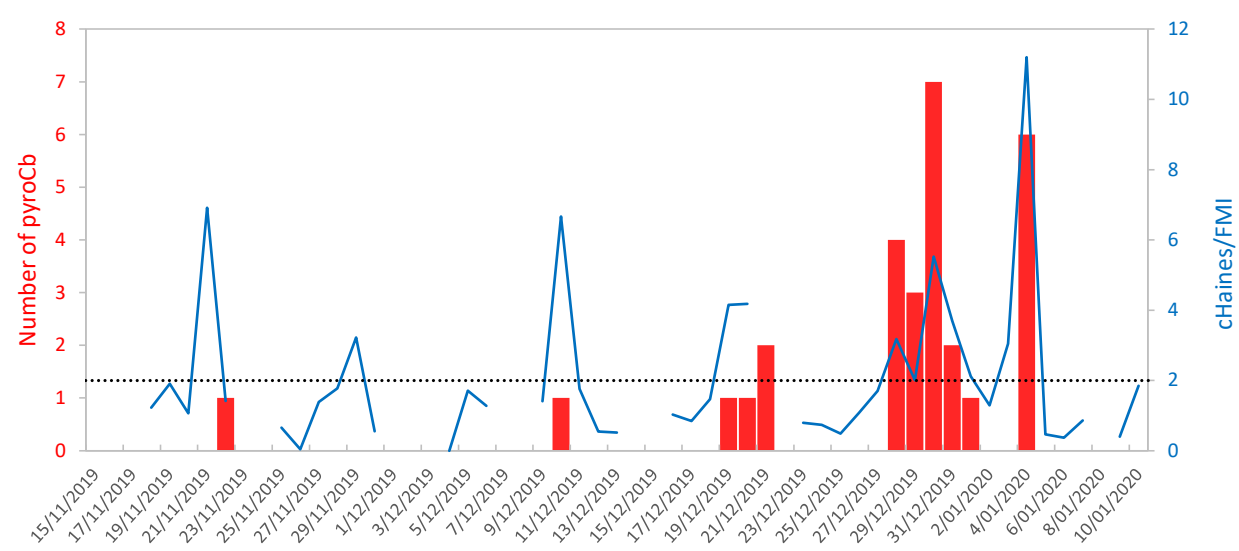

Figure 7. Time series of cHaines divided by FMI (blue) plotted against pyroCb occurrence data (red) for the period 15 November 2019 - 10 January 2020. The black dotted line indicates cHaines $=2 \times F M I$. 


\section{CONCLUSION}

The ability of several simple fire weather indices to discern conditions necessary for pyroCb development was examined. It was found that the $F M I$ and cHaines index did the best job of discriminating conditions conducive to pyroCb development: pyroCbs occurred only on days with $F M I<6$ and cHaines $\geq 8$. The spread index and $H D W$ were found to discriminate conditions less well, possibly due to their inclusion of wind speed, as sufficiently strong winds may affect pyroCb formation. Based on these results, a new measure defined by the quotient of cHaines and FMI was introduced, and it was found that pyroCb formation was strongly associated with days on which the continuous Haines index was twice the fuel moisture index, or more.

The results presented here further highlight the remarkable utility of very simple indices to provide guidance relating to complex wildfire phenomena. Fire weather variables such as temperature and relative humidity (which can be easily combined to give the $F M I$ ) and cHaines are routinely available in operational fire weather reports, and so a rule of thumb like "cHaines $\geq 2 \times F M I$ " provides a highly parsimonious way for operational personnel to gauge the likelihood of dangerous escalations in the state of an active wildfire.

\section{ACKNOWLEDGMENTS}

This paper builds upon work presented at the $2^{\text {nd }}$ San Jose State University Fire Weather Research Workshop, organised by Craig Clements and Adam Kochanski from the SJSU Wildfire Interdisciplinary Research Center.

\section{REFERENCES}

Abram, N.J., Henley, B.J., Gupta, A.S., Lippmann, T.J., Clarke, H., Dowdy, A.J., Sharples, J.J., Nolan, R.H., Zhang, T., Wooster, M.J., Wurtzel, J.B., 2021. Connections of climate change and variability to large and extreme forest fires in southeast Australia. Communications Earth \& Environment 2(1), 1-17.

Badlan, R.L., Sharples, J.J., Evans, J.P., McRae, R.H., 2021. Factors influencing the development of violent pyroconvection. Part II: fire geometry and intensity. International Journal of Wildland Fire, 30: 498-512

Di Virgilio, G., Evans, J.P., Blake, S.A., Armstrong, M., Dowdy, A.J., Sharples, J.J., McRae, R., 2019. Climate change increases the potential for extreme wildfires. Geophysical Research Letters 46(14), 8517-8526.

Fromm, M., Lindsey, D.T., Servranckx, R., Yue, G., Trickl, T., Sica, R., Doucet, P., Godin-Beekmann, S., 2010. The untold story of pyrocumulonimbus. Bulletin of the American Meteorological Society 91(9), 11931210.

McRae, R.H., Sharples, J.J., Fromm, M., 2015. Linking local wildfire dynamics to pyroCb development. Natural Hazards and Earth System Sciences 15(3), 417-428.

Mills, G.A., McCaw, L., 2010. Atmospheric stability environments and fire weather in Australia-Extending the Haines Index. Australian Government, Bureau of Meteorology.

Monteith, J., Unsworth, M., 2013. Principles of environmental physics: plants, animals, and the atmosphere. Academic Press.

Peterson, D.A., Fromm, M.D., McRae, R.H., Campbell, J.R., Hyer, E.J., Taha, G., Camacho, C.P., Kablick, G.P., Schmidt, C.C., DeLand, M.T., 2021. Australia's Black Summer pyrocumulonimbus super outbreak reveals potential for increasingly extreme stratospheric smoke events. npj Climate and Atmospheric Science 4(1), 116.

Potter, B.E., 2005. The role of released moisture in the atmospheric dynamics associated with wildland fires. International Journal of Wildland Fire 14(1), 77-84.

Sharples, J.J., McRae, R.H., Weber, R.O., Gill, A.M., 2009. A simple index for assessing fuel moisture content. Environmental Modelling \& Software 24(5), 637-646.

Sharples, J.J., McRae, R.H., 2011. Evaluation of a very simple model for predicting the moisture content of eucalypt litter. International Journal of Wildland Fire 20(8), 1000-1005.

Sharples, J.J., McRae, R.H., 2013. A fire spread index for grassland fuels. In J. Piantadosi, R. Anderssen, and J. Boland (eds.) MODSIM2013, 20th International Congress on Modelling and Simulation, Modelling and Simulation Society of Australia and New Zealand, December 2013. pp. 249-255.

Sharples, J.J., Cary, G.J., Fox-Hughes, P., Mooney, S., Evans, J.P., Fletcher, M.S., Fromm, M., Grierson, P.F., McRae, R., Baker, P., 2016. Natural hazards in Australia: extreme bushfire. Climatic Change 139(1), 8599.

Sharples, J.J., 2019. Evaluation of a simple rate of spread index applied to Canadian fuel types. In Elsawah, S. (ed.) MODSIM2019, 23rd International Congress on Modelling and Simulation. Modelling and Simulation Society of Australia and New Zealand, December 2019, pp. 788-794.

Srock, A.F., Charney, J.J., Potter, B.E., Goodrick, S.L., 2018. The hot-dry-windy index: A new fire weather index. Atmosphere 9(7), 279.

Tory, K.J., Kepert, J.D., 2021. Pyrocumulonimbus Firepower Threshold: Assessing the atmospheric potential for pyroCb. Weather and Forecasting 36(2), 439-456. 